\title{
O Fundo Estadual de Recursos Hídricos do Estado do Amazonas: uma análise acerca de seu funcionamento e gerenciamento
}

\section{Françoan de Oliveira Dias ${ }^{1}$, Richard Coelho de Paulo ${ }^{2}$, Wallace de Sousa Santos ${ }^{1}$ e Flávio Wachholz ${ }^{1}$}

\author{
${ }^{1}$ Universidade do Estado do Amazonas. Escola Normal Superior. Avenida Djalma \\ Batista, 2470. Chapada. Manaus-AM, Brasil (CEP 69050-010). E-mail: \\ francoan.dias@gmail.com. \\ ${ }^{2}$ Universidade do Estácio de Sá. Faculdade Estácio do Amazonas. Avenida \\ Constantino Nery, 3693. Chapada, Manaus-AM, Brasil (CEP 69025-315).
}

Resumo. Neste estudo buscou-se analisar as operações financeiras e o gerenciamento atual do Fundo Estadual de Recursos Hídricos do Amazonas, instrumento da Política Estadual de Recursos Hídricos. Com relação aos procedimentos metodológicos empregados, a pesquisa caracteriza-se qualitativa e exploratória, por meio de um estudo de caso, subsidiada pelas análises bibliográficas e documentais. Os resultados encontrados apontam que o regimento interno do fundo traz procedimentos necessários para sua operacionalização, no entanto, algumas questões deixam de ser previstas, entre elas a constituição das receitas do fundo. Em relação às receitas e despesas que fizeram parte do fundo, elas eram oriundas do PROGESTÃO - 1ํㅡㄴ Ciclo. No que se refere às receitas que deixam de integrar o fundo, destacam-se as compensações financeiras pela exploração mineral e pela utilização de recursos hídricos e as multas aplicadas com base na Lei $\mathrm{n}-3.167 / 2007$. Outras que poderiam integrar, mas que não estão previstas, são os royalties do petróleo e do gás natural. Conclui-se que, estes obstáculos resultaram na operacionalização insatisfatória do fundo em decorrência de um sistema estadual de gerenciamento de recursos hídricos que necessita de fortalecimento e consolidação, além de um conselho estadual de recursos hídricos atuante nessa questão.

Palavras-chave: Instrumento econômico-financeiro; Financiamento de programas e projetos; Recuperação de bacias hidrográficas; Gestão hídrica.

Abstract. The Amazon State Water Resources Fund: An analysis of its functioning and management. In this study, we sought to analyze the financial operations and current management of the State Water Resources Fund of Amazonas, an instrument of the State Water Resources Policy. With regard to the methodological procedures employed, the research is
Recebido

$14 / 07 / 2021$

Aceito

$13 / 12 / 2021$

Publicado

$31 / 12 / 2021$

Acesso aberto

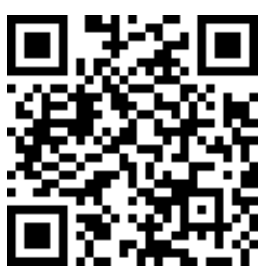

ORCID

(1) 0000-0003-4129-7034 Françoan de Oliveira Dias

D) 0000-0003-1081-5951

Richard Coelho de Paulo

(D) $0000-0002-9869-2548$ Wallace de Sousa Santos

(D) 0000-0003-1241-4844 Flávio Wachholz

ISSN 2359-1412/RBGAS-2021-0088/2021/8/20/18/1553

Rev. Bras. Gest. Amb. Sustent.

http://revista.ecogestaobrasil.net 
characterized as qualitative and exploratory, through a case study, supported by bibliographical and documentary analyzes. The results found show that the fund's internal regulations provide the necessary procedures for its operation, however, some issues are no longer foreseen in it, including the constitution of the fund's revenues. Regarding the income and expenses that were part of the fund, they came from Progestão 1st Cicle. With regard to revenues that are no longer part of the fund, the following stand out: the financial compensation for Mineral Exploration and the Use of Water Resources and the fines applied based on Law No. 3,167/2007. Others that could be integrated, but which are not foreseen, are the royalties from oil and natural gas. It is concluded that, these obstacles resulted in the unsatisfactory operationalization of the fund due to a state water resources management system that needs strengthening and consolidation, in addition to a state water resources council acting on this issue.

Keywords: Economic-financial instrument; Program and project financing; River basin recovery; Water management.

\section{Introdução}

A partir da promulgação da Lei no 9.433/1997 (Brasil, 1997), intitulada como Lei das Águas, institui-se a Política Nacional de Recursos Hídricos (PNRH), além de criar o Sistema Nacional de Gerenciamento de Recursos Hídricos (SINGREH).

Esse novo arcabouço legal traz um novo panorama na gestão dos recursos hídricos do país, proporcionando os usos múltiplos das águas, de forma descentralizada e participativa, contando com a participação do Poder Público, dos usuários e das comunidades (ANA, 2020).

Segundo Dias (2020), os estados e o Distrito Federal passaram a instituir suas próprias políticas de recursos hídricos nas mesmas prerrogativas da PNRH e do SINGREH. Para implementação dessas políticas, instituíram-se instrumentos para a gestão de recursos hídricos, tendo como base o art. 5o, da Lei no 9.433/1997 (Brasil, 1997).

Dentre os instrumentos, destacam-se os planos de recursos hídricos, o enquadramento dos corpos de água em classes, segundo os usos preponderantes da água, a outorga dos direitos de uso de recursos hídricos, a cobrança pelo uso de recursos hídricos e o Sistema de Informações sobre Recursos Hídricos (Brasil, 1997).

Outros instrumentos também foram instituídos, dentre eles, destacam-se os fundos estaduais/distrital de recursos hídricos, cuja finalidade é dar suporte financeiro às políticas/sistemas de recursos hídricos (Dias, 2020).

Rodrigues (2007) salienta que a utilização do fundo como um financiador da política estadual está ligado diretamente à capacidade do Estado em assegurar que os recursos realmente retornem aos seus beneficiários, ao desenvolvimento dos comitês de bacia e como eles aplicam esses recursos disponibilizados pelo fundo.

Embora, este tipo de fundo, naturalmente, não esteja sujeito às normas federais, é o instrumento que a maior parte dos Estados da Federação elegeram para a acumulação de recursos financeiros para a aplicação em ações estruturais e não estruturais para a gestão de recursos hídricos, tendo como principais fontes a cobrança pelo uso de recursos hídricos e a Compensação Financeira pela Utilização de Recursos Hídricos (CFURH) (Brasil, 2015). 
Em valores, no ano de 2019 foram cobrados pelo uso de recursos hídricos de domínio da União cerca de $\mathrm{R} \$ 728,12$ milhões, conforme informe anual 2020, da Conjuntura dos Recursos Hídricos no Brasil (ANA, 2020). E de repasses de CFURH neste mesmo ano, aos 21 Estados e Distrito Federal beneficiários, segundo dados da Agência Nacional de Energia Elétrica (ANEEL, 2020), o montante alcançou R 405,52 milhões.

Com relação ao Estado do Amazonas, sua política de recursos hídricos foi instituída por meio da Lei no 32.712/2001 (Amazonas, 2001), que posteriormente foi reformulada pela Lei no 3.167/2007 (Amazonas, 2007). Posteriormente, o Decreto $\mathrm{n}^{\mathrm{o}}$ 28.678/2009 (Amazonas, 2009) regulamenta essa lei.

Dentre os instrumentos dessa política estadual, criou-se o Fundo Estadual de Recursos Hídricos (FERH), cuja aplicação dos recursos seguirá as diretrizes da Política Estadual de Recursos Hídricos e atenderá aos objetivos e metas do Plano Estadual de Recursos Hídricos, estabelecidos por bacias hidrográficas, devendo ser compatibilizados com o Plano Plurianual, a Lei de Diretrizes Orçamentárias e com o Orçamento Anual do Estado (Amazonas, 2001).

0 art. 32, § 1ํㅡㄹ da Lei no 3167/2007 (Amazonas, 2007), estabelece que o fundo será gerido pela Secretaria de Estado do Meio Ambiente (SEMA), incumbida de emitir as Instruções Normativas visando normatizar sua operacionalização.

Outro importante instrumento legal deu-se mediante a publicação da Portaria SEMA no 120/2019 (Amazonas, 2019), que instituiu o Regimento Interno do Fundo Estadual de Recursos Hídricos do Amazonas, trazendo critérios para o financiamento de programas e ações no âmbito dos recursos hídricos, de modo a promover a melhoria e proteção dos corpos d'água e bacias hidrográficas.

Diante do exposto, este estudo teve como finalidade analisar as operações financeiras e o gerenciamento atual do Fundo Estadual de Recursos Hídricos do Amazonas, assim como suas perspectivas futuras no âmbito da Gestão de Recursos Hídricos do estado.

Neste ínterim, pressupõe-se que verificar o panorama e gerenciamento Fundo Estadual de Recursos Hídricos são essenciais para realizar um diagnóstico atual e propor mudanças, beneficiando assim o financiamento de programas e projetos voltados para a proteção dos corpos hídricos do Estado do Amazonas.

Para tanto, realizou-se análise de documentos técnicos e administrativos de órgãos públicos, estaduais e federais, que participam da gestão e operacionalização dos recursos financeiros do fundo, além do conhecimento de outros autores acerca dessa temática, em conformidade com outros fundos de recursos hídricos brasileiros.

\section{Procedimentos metodológicos}

A pesquisa bibliográfica foi fundamentada a partir de livros, artigos, teses, dissertações, monografias, cadernos de capacitação em recursos hídricos da Agência Nacional de Águas e Saneamento Básico e demais publicações acadêmicas que envolvessem o tema. Buscaram-se ainda publicações no Diário Oficial da União (DOU) e no Diário Oficial do Estado (DOE) do Amazonas, que incluiu leis, resoluções, instruções normativas, portarias, contratos e demais publicações oficiais que tratam dos repasses financeiros ao Fundo Estadual de Recursos Hídricos.

A pesquisa documental abrangeu arquivos públicos, que necessitaram de tratamento dos dados para posterior análise. Estes arquivos, mais precisamente processos administrativos, foram solicitados, com base na Lei no 12.527/2011 (Brasil, 2011) e no Decreto no 36.819/2016 (Amazonas, 2016), que tratam do acesso a informações públicas, nos seguintes órgãos estaduais, que têm relação direta com o Fundo Estadual de Recursos Hídricos, a Secretaria de Estado do Meio Ambiente (SEMA), a Secretaria de Estado da Fazenda (SEFAZ), o Instituto de Proteção Ambiental do Amazonas (IPAAM) e o Tribunal de 
Contas do Estado (TCE). Já em âmbito federal, essas informações foram disponibilizadas, pela Agência Nacional de Águas e Saneamento Básico (ANA), Agência Nacional de Energia Elétrica (ANEEL), Agência Nacional de Mineração (ANM) e Agência Nacional de Petróleo, Gás Natural e Biocombustíveis (ANP).

Os acessos à informação tiveram os seguintes protocolos e-SIC SEFAZ no 65/2019, e-SIC SEMA no 44/2019, e-SIC SEMA no 113/2019, e-SIC IPAAM no 42/2019, e-SIC IPAAM no 671/2019 e e-SIC ANEEL no 48700004369201868. Outros dados foram disponibilizados mediante consulta aos portais eletrônicos institucionais, entre eles o Sistema de Arrecadação de Compensação Financeira pela Exploração Mineral (CFEM), da Agência Nacional de Mineração (ANM), o Sistema de distribuição dos royalties da Agência Nacional de Petróleo, Gás Natural e Biocombustíveis (ANP) e o Portal da Transparência Fiscal do Amazonas. Também foram obtidos dados mediante solicitação ao Tribunal de Contas do Estado do Amazonas (TCE-AM), em 29/01/2019, tendo como respostas o Ofício no 234/2019-GPTCE/AM, de 25/02/2019, o Ofício no 620/2019-SECEX, de 09/09/2019, e a Informação no 37/2019/DICOI (Amazonas, 2019; Brasil, 2019; TCE-AM, 2020).

Por fim, outros dados foram disponibilizados pelo Conselho Estadual de Recursos Hídricos (CERH) e pelos Comitês de Bacia Hidrográfica (CBHs), entes que integram o Sistema Estadual de Gerenciamento de Recursos Hídricos do Amazonas (SEGRH).

Os dados obtidos, com base no tipo de pesquisa, foram avaliados por meio da técnica análise de conteúdo, que segundo Silva e Fossá (2015), representa um conjunto de técnicas de análise das comunicações, sendo que no caso deste estudo se deu pelos documentos coletados e publicações acerca da temática.

\section{Resultados e discussão}

O regimento interno do Fundo Estadual de Recursos Hídricos do Amazonas

O Fundo Estadual de Recursos Hídricos do Amazonas foi instituído por meio da Lei no 2.712/2001 (Amazonas, 2001), reformulada pela Lei no 3.167/2007 (Amazonas, 2007), e regulamentado pelo Decreto no 28.678/2009 (Amazonas, 2009). Segundo essas normas, o fundo é o instrumento econômico-financeiro de apoio à implantação da Política Estadual de Recursos Hídricos por meio do financiamento de programas e ações, de modo a promover a melhoria e a proteção dos corpos d'água e de suas bacias hidrográficas.

Por meio da Portaria SEMA no 120/2019 (Amazonas, 2009), é instituído o regimento interno do FERH, considerando a necessidade de se estabelecer procedimentos para a sua operacionalização. Esta portaria divide-se da seguinte forma, caracterização e finalidades do FERH, atribuições da Comissão Gestora, aplicação dos recursos financeiros, seleção de projetos e prestação de contas.

A Secretaria de Estado do Meio Ambiente (SEMA) é o órgão gestor do FERH,

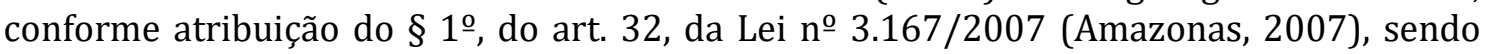
que, com a publicação do regimento, passou a ser administrado por uma comissão composta pelo: (i) o titular da Secretaria Executiva (SECEX), que o coordenará; (ii) o titular da Secretaria Executiva Adjunta (SEAGA); (iii) o titular da Assessoria de Recursos Hídricos (ASSHID); e (iv) 0 titular do Departamento Financeiro (DEFIN).

Cabe destacar que a conta bancária do FERH é movimentada, conjuntamente, pelo Coordenador do Fundo e pelo titular do Departamento Financeiro (DEFIN), sendo estes os responsáveis pela ordenação de despesas. Ressalta-se ainda que, para cumprimento de suas atribuições, o FERH contará com o apoio técnico de órgãos e entidades da Administração Pública Estadual Direta e Indireta e demais instituições de ensino e pesquisa.

Outro ponto importante refere-se às atribuições desta comissão gestora, que além de administrar o Fundo, define critérios para a gestão e controle orçamentário, financeiro 
e patrimonial, além de aprovar também os planos anual e plurianual de aplicação dos recursos.

Salienta-se também que entre outras atribuições da comissão, irá promover a captação e destinação dos recursos do FERH, além de realizar a análise técnica preliminar dos projetos encaminhados por demanda induzida ou espontânea.

A comissão ainda irá apreciar e votar o orçamento anual e a prestação de contas, fiscalizando o planejamento aprovado, além de propor ou requerer moções, diligências e esclarecimentos necessários ao acompanhamento da execução dos projetos financiados pelo FERH.

O coordenador da Comissão Gestora tem atribuições importantes nos atos do FERH, dentre elas: (i) representá-lo em todos os atos jurídicos em que for parte; (ii) assinar, juntamente com o titular do Departamento Financeiro, as ordens bancárias, termos de parceria, convênios e outros compromissos relacionados à utilização dos recursos do Fundo, até o limite do orçamento anual; (iii) encaminhar a prestação de contas ao TCE e ao CERH; e (iv) conduzir os projetos aprovados pela comissão do Fundo para a Secretaria Executiva do CERH.

Dos demais membros da comissão cabem, principalmente, (i) resolver as questões de ordem administrativa, (ii) manter atualizada a documentação e escrituração contábil, (iii) executar os serviços de contabilidade, (iv) elaborar os balancetes mensais e demonstrativos de contas, (v) promover a prestação de contas de aplicação dos recursos do FERH, encaminhando à apreciação e aprovação do CERH, e (iv) elaborar proposta de orçamento anual e do plano plurianual.

Destaca-se ainda que a Comissão Gestora elaborará relatório anual de desempenho das atividades do FERH, o qual será submetido à apreciação do CERH, no início ou fim do exercício, ou sempre que solicitado pelo Plenário.

Quanto à aplicação dos recursos financeiros do FERH, o regimento prevê que deverão ser aplicados através da formalização de acordo, convênios, contratos administrativos, termos de cooperação técnica e financeira pelos órgãos públicos da Administração Direta e Indireta do Estado e dos Municípios bem como de entidades privadas sem fins lucrativos.

Ressalta-se que o produto da cobrança pela utilização de recursos hídricos será aplicado em serviços e obras hidráulicas previstos no Plano Estadual de Recursos Hídricos, preferentemente nas bacias hidrográficas em que forem efetivamente arrecadados.

0 regimento ainda prevê que até $30 \%$ (trinta por cento) do produto da cobrança pelo uso da água poderão ser aplicados em bacia hidrográfica diversa daquela em que se deu sua efetiva arrecadação, devendo passar por deliberação do CERH, diferentemente da previsão do inciso II, do art. 36, da Lei no 3.167/2007 (Amazonas, 2007), que destinava até $50 \%$ desse valor arrecadado.

$\mathrm{Na}$ aplicação dos recursos do fundo deverão ser consideradas as metas do Plano Estadual de Recursos Hídricos, em fase de consolidação. Deste modo, serão priorizadas as seguintes aplicações de recursos financeiros do FERH em planos, programas ou projetos que contemplem: educação ambiental, controle e monitoramento ambiental, recuperação ambiental, proteção dos recursos hídricos, conservação da biodiversidade, unidades de conservação, desenvolvimento florestal, pesquisa, desenvolvimento tecnológico, desenvolvimento institucional, desenvolvimento de políticas públicas ambientais, instrumentos e meios legais e econômicos, assim como em despesas correntes pertinentes a atividades da SEMA e do IPAAM.

Ressalta-se que com relação às despesas correntes da SEMA e do IPAAM, a finalidade da aplicação das receitas do FERH/AM não é esta, visto que cada órgão tem seu orçamento de manutenção de suas atividades. Nesse sentido, o Ministério da Economia (2020) enfatiza e exemplifica que as despesas correntes de manutenção das atividades dos 
órgãos da administração pública, são, como por exemplo, despesas com pessoal, juros da dívida, aquisição de bens de consumo, serviços de terceiros, manutenção de equipamentos, despesas com água, energia, telefone etc. Estão nesta categoria as despesas que não concorrem para ampliação dos serviços prestados pelo órgão, nem para a expansão das suas atividades.

Mais adiante, cita-se também que em casos de situação de emergência, poderá a SEMA ou o IPAAM realizar despesas ad referendum do CERH, no prazo máximo de setenta e duas horas, desde que relacionadas às finalidades previstas no art. 35 , da Lei $\mathrm{n}^{\mathbf{o}}$ 3.167/2007 (Amazonas, 2007).

No que diz respeito ao saldo positivo do FERH apresentado em balanço anual, será transferido para o exercício seguinte a crédito do mesmo fundo, considerando que sua movimentação e a prestação de contas estão sujeitas à fiscalização do TCE.

Quanto à seleção de projetos por demanda espontânea, deverão ser endereçados ao Presidente do CERH, que os encaminhará ao Coordenador da Comissão Gestora do FERH para a análise técnica preliminar relacionada à adequação do projeto e pertinência temática, citadas anteriormente. Destaca-se ainda que, poderão participar da seleção: instituições públicas pertencentes à administração direta ou indireta, em seus diversos níveis (federal, estadual e municipal); empresas públicas voltadas à pesquisa e extensão; Instituições de Ensino Superior, Pesquisa e Extensão, sem fins lucrativos e Instituições Comunitárias de Educação Superior; instituições privadas brasileiras sem fins lucrativos que possuam no mínimo cinco anos de existência legal, e, cujas atribuições contemplem a atuação em áreas do Meio Ambiente, podendo ser, ONG's, OSCIP's; organização de base (sindicatos, associações de produtores, associação de reposição florestal, cooperativas ou outras à exceção de clubes e associações de servidores ou quaisquer entidades congêneres).

É importante esclarecer que somente poderão ser assinados convênios, termos de parceria ou acordos relacionados ao FERH, aqueles que forem aprovados pela plenária do CERH e conforme a disponibilidade orçamentária do fundo, sendo que estes resultados da seleção serão publicados no DOE ou em sítio eletrônico da SEMA.

Estes projetos a serem apoiados pelo FERH deverão ser elaborados com observância aos seguintes requisitos técnicos (i) objetivos gerais e específicos do projeto; (ii) justificativa socioambiental; (iii) metas a serem atingidas e respectivos indicadores; (iv) etapas ou fases de execução; (v) custo total do projeto; (vi) plano de aplicação; (vii) cronograma de desembolso financeiro; e (viii) licença ambiental, se for o caso.

No que tange a prestação de contas dos projetos, todas as instituições que utilizem, de qualquer forma, recursos do FERH prestarão contas até 30 dias após o encerramento do convênio ou acordo de parceria firmado.

Percebe-se, conforme exposto acima, um grande passo para o avanço da Gestão de Recursos Hídricos do Estado do Amazonas com a publicação do regimento interno do FERH, importante instrumento econômico-financeiro para o financiamento de programas e ações do Plano Estadual de Recursos Hídricos, criado em 2001 e que final de 2019 o órgão gestor, neste caso a SEMA, formalizou os procedimentos gerais para sua operacionalização.

Contudo, essa portaria, instituindo o regimento do FERH, ainda se apresenta em termos gerais, um exemplo disso é o não apontamento de quais receitas e percentuais que deverão compor o Fundo, pois, para que haja boa operacionalização, faz-se necessário o repasse adequado desses recursos financeiros, entre eles, que poderiam estar contemplados nesta portaria, de acordo com o art. 34, da Lei no 3.167/2007 (Amazonas, 2007), que trata das receitas do FERH, podemos citar, principalmente, aquelas que estão deixando de compor o Fundo por falta de formalização: 
- As transferências da União destinadas à execução de planos e programas de recursos hídricos de interesse comum (inciso II). Nesta situação, poderia ocorrer repasses financeiros da ANA diretamente ao FERH de alguns programas e projetos que já estão sendo realizados, como por exemplo, o Programa de Estímulo à Divulgação de Dados de Qualidade de Água (Qualiágua);

- Parte da compensação financeira que os Municípios e o Estado recebem com relação aos aproveitamentos de outros recursos minerais, para aplicação exclusiva em levantamentos, estudos e programas de interesse do gerenciamento de recursos hídricos subterrâneos (inciso III). Com relação à Compensação Financeira pela Exploração de Recursos Minerais (CFEM), o regimento do FERH poderia regularizar qual seria esse percentual para a realização dos levantamentos, estudos e programas da Gestão de Recursos Hídricos Subterrâneos;

- O produto da aplicação de multas cobradas dos infratores da legislação sobre recursos hídricos (inciso X). Neste caso, o IPAAM, órgão executor da PERH, já aplica multas aos infratores de recursos hídricos com base no art. 68, da Lei no 3.167/2007, porém essas receitas arrecadadas com as infrações não são direcionadas ao FERH, e, sim, ao Fundo Estadual de Meio Ambiente (FEMA), cuja justificativa é a falta de formalização de procedimentos, que neste caso, poderia estar descrito no regimento atual do Fundo;

- A compensação financeira que o Estado receber com relação aos aproveitamentos hidroenergéticos em seu território e as compensações similares recebidas por Municípios e repassadas ao Fundo mediante convênio (inciso XI). Nesta situação, o Estado do Amazonas recebe a Compensação Financeira pela Utilização de Recursos Hídricos da Usina Hidrelétrica de Balbina (CFURH), desde 1991, sendo que em tese, com a criação do FERH, em 18 de dezembro de 2001, mediante a promulgação da Lei no $2.712 / 2001$, o repasse financeiro desta compensação deveria ir para o fundo, a partir do momento de sua criação, previsão esta encontrada no inciso XI, do art. 37, da primeira versão da Política Estadual de Recursos Hídricos, que foi atualizada pela Lei no 3.167/2007.

Conforme supramencionado, essas seriam as possibilidades de receitas financeiras que poderiam compor o FERH atualmente, segundo os dados obtidos que serão detalhados mais adiante. Consequentemente, seria possível elaborar o Plano de Aplicação do Fundo, com base nos planos de outros Estados, adequando ao arranjo institucional do Amazonas, visando fortalecer e estruturar, caso necessário, o SEGRH, o que incluiria financiamento das ações dos Comitês de Bacias Hidrográficas dos Rios Puraquequara e Tarumã-Açu.

No entanto, a regulamentação das receitas do Fundo não pode ser feita internamente pela SEMA por meio de portaria, que é a realidade atual. Requer que a lei seja alterada de modo a explicitar os percentuais ou, o que parece mais plausível, que seja publicado decreto do governo do estado regulamentando o repasse ao FERH.

\section{As receitas e despesas do FERH/AM decorrentes do PROGESTÃo - 1 Ciclo}

Por meio do Contrato no 115/ANA/2013 - PROGESTÃO, a ANA transferiu recursos financeiros à Secretaria de Mineração, Geodiversidade e Recursos Hídricos (SEMGRH), no âmbito do Progestão, na forma de pagamento pelo alcance de metas de gerenciamento de recursos hídricos, mediante o cumprimento de metas de gestão do programa.

A adesão do programa pelo Estado do Amazonas ocorreu por meio da publicação no DOE do Decreto no $34.059 / 2013$, tendo como entidade coordenadora à SEMGRH, onde a tipologia de gestão empregada foi a "A" (Amazonas, 2013). Ressalta-se que o 1 o Ciclo ocorreu de 2013 a 2017, sendo estimado o montante para esse período foi de 
$\mathrm{R} \$ 3.750 .000,00$ (três milhões e setecentos e cinquenta mil reais), caso o cumprimento de metas fosse $100 \%$.

Inicialmente no contrato supramencionado foi previsto que as parcelas de recursos financeiros seriam depositadas em conta-corrente da SEMGRH, denominada Conta PROGESTÃO. No entanto, com a publicação do 1 o Termo Aditivo ao Contrato no115/ANA/2013-PROGESTÃO, de 31 de março de 2014, a ANA passaria a transferir os recursos financeiros ao Fundo Estadual de Recursos Hídricos (FERH/AM), em conta específica, sendo que esses repasses só ocorreriam quando comprovado a regularidade fiscal da Secretaria e do FERH.

Com a publicação do $2^{\text {o }}$ Termo Aditivo ao Contrato no 115/ANA/2013PROGESTÃO, de 22 de dezembro de 2015, é alterado a Entidade Estadual de SEMGRH para a Secretaria de Estado do Meio Ambiente (SEMA), em decorrência da mudança na estrutura administrativa do Poder Executivo do Amazonas, promovido pela Lei $\mathrm{n}^{\mathrm{o}}$ 4.163/2015, que extingue a SEMGRH e transforma a Secretaria de Estado do Meio Ambiente e Desenvolvimento Sustentável (SDS) em SEMA. A Lei no 4.193/2015 transfere as funções relacionadas aos recursos hídricos para a SEMA.

O $3^{\circ}$ Termo Aditivo ao Contrato no 115/ANA/2013-PROGESTÃO, de 11 de dezembro de 2017, prorroga a vigência do contrato (Cláusula Sétima) do 1o Ciclo Progestão para 30 de setembro de 2018. Anteriormente essa data estava prevista para até 31 de março de 2018.

Em 2013, foi liberada a primeira parcela do programa, após assinatura do contrato. Consequentemente, de acordo com o Relatório Progestão (2018), que apresenta a síntese do $1^{\mathrm{o}}$ Ciclo, durante o período 2013-2017, os repasses ao FERH ficaram da seguinte forma:

- Ano 2013: Aprovação do quadro de metas $=100 \%-1$ a parcela $=\mathrm{R} \$$ $750.000,00$;

- Ano 2014: Nota final de avaliação $=80 \%-2^{\underline{a}}$ parcela $=\mathrm{R} \$ 600.000,00$;

- Ano 2015: Nota final de avaliação = 85,5\% - 3르 parcela $=\mathrm{R} \$ 641.250,00$;

- Ano 2016: Nota final de avaliação $=87,63 \%$ - 4를 parcela $=\mathrm{R} \$ 657.225,00$; e

- Ano 2017: Nota final de avaliação = 93,05\% - 5 - parcela $=\mathrm{R} \$ 697.875,00$.

Deste modo, no 1을 Ciclo foram transferidos ao Fundo Estadual de Recursos Hídricos o montante de $\mathrm{R} \$ 3.346 .350,00$. Com relação à aplicação desses recursos do FERH, os gastos realizados no estado até o ano de 2017 giraram em torno de $\mathrm{R} \$ 1.311 .026,82$. Esse valor se deu principalmente com despesas de contratação de pessoal, aquisição de material permanente e de consumo, diárias e passagens, programa de perfuração de poços no estado, realização de eventos e ações de capacitação, além da manutenção da rede hidrometereológica. Até dezembro de 2017, devido aos rendimentos financeiros, de acordo com a SEMA, o saldo na conta Progestão era de R \$1.556.028,37.

Para operacionalização das metas, ações e indicadores constantes no Plano de Trabalho do $1^{\text {o }}$ Ciclo do Progestão, firmou-se Contrato de Gestão no 01/2016, entre o FERH e a Agência Amazonense de Desenvolvimento Econômico e Social (AADES), com o intuito de executar o plano, entre as ações que podemos citar a necessidade de contratação de bolsistas para reforçar o quadro de pessoal. Este contrato teve duração de 24 meses a contar da data de assinatura do contrato.

Quanto aos recursos orçamentários e financeiros para o cumprimento deste Contrato de Gestão e de acordo com o cronograma de desembolso constante no Plano de Trabalho, foram disponibilizados inicialmente o valor de $\mathrm{R} \$ 1.935 .238,82$, por meio de Unidade Orçamentária 30702, Programa de Trabalho 18.541.3248.2593.0001, Fonte 
Recurso 02850000, Natureza de Despesa 33504199, tendo sido emitido pelo FERH, em 18 de abril de 2016 a Nota de Empenho no 2016NE00002, cujo valor era de R\$ 500 mil reais, ficando o restante a ser empenhado no decorrer do cumprimento do plano pela AADES.

No dia 19 de dezembro de 2016, o FERH, por meio de seu ordenador de despesa, e a AADES, assinam o 1ำ Termo Aditivo ao Contrato de Gestão no 01/2016, com a finalidade de estruturar o Plano de Trabalho, havendo supressão das rubricas de passagens aéreas interestaduais, municipais e fluviais correspondente ao valor de $\mathrm{R} \$ 135$ mil reais e de aluguel de lanchas voadeira no valor de $\mathrm{R} \$ 18$ mil reais, bem como a inclusão da rubrica de materiais permanentes no valor de $\mathrm{R} \$ 38$ mil reais e remanejamento do quantitativo profissional de Agente de Pesquisa para o quantitativo de três e inclusão de um artífice.

Salienta-se ainda que esse Termo Aditivo supramencionado foi mantido pelo saldo remanescente do contrato original, cujo valor correspondia a $\mathrm{R} \$ 1.935 .238,82$, havendo supressão no valor do contrato original de $\mathrm{R} \$ 123.252,64$, restando $\mathrm{R} \$ 1.811 .986,18$ como total geral do orçamento deste aditivo.

Sendo assim, é importante frisar que apesar dos recursos do 1 o Ciclo do Progestão terem ido para o FERH, a sua aplicação visa a atender as diretrizes da Política Estadual de Recursos Hídricos e os objetivos e metas do Plano Estadual de Recursos Hídricos, conforme ordena o art. 33, da Leino $3.167 / 2007$, que trata das aplicações dos recursos do Fundo, assim como da aplicação exclusiva em ações de fortalecimento institucional e de gerenciamento de recursos hídricos, conforme estabelecido nas diretrizes do Progestão, programa este de escala nacional.

Nesse entendimento, o Progestão dá inteira liberdade ao governo do Estado do Amazonas em aplicar os recursos do programa na forma que achar prioritário. Vale pressupor que um dos motivos que fizeram com que os repasses do $2^{\circ}$ Ciclo do Progestão não fossem para a conta específica do FERH-AM foi o excesso de burocracia, a exemplo do Progestão em Minas Gerais.

O Progestão visa o fortalecimento do Sistema Estadual de Gestão e se alinha perfeitamente aos objetivos do Fundo Estadual. Os recursos do Progestão acabam sendo utilizados em sua maior parte em recursos humanos, sendo que de acordo com a legislação deveriam ser aplicados em sua maior parte em ações de melhoria da gestão, fortalecimento da PERH e de execução do Plano Estadual de Recursos Hídricos.

\section{As possíveis receitas que poderiam integrar as do FERH-AM}

A compensação financeira pela utilização dos recursos hídricos da Usina Hidrelétrica de Balbina. O inciso XI, do art. 34, da Lei oㅡ 3.167/2007, prevê como uma das receitas do FERH, a compensação financeira que o estado receber com relação aos aproveitamentos hidroenergéticos em seu território e as compensações similares recebidas por Municípios e repassadas ao Fundo mediante convênio.

Nesse cenário, o Estado do Amazonas recebe CFURH da Usina Hidrelétrica de Balbina, que de acordo com o Relatório de Administração da Eletrobras Distribuição Amazonas (2017), concessionária que administra esta UHE, que tem uma potência contratada de 130,1 MW, média potência garantida de 127,520 MW, disponibilidade de potência contratada 98,01\%, quantidade de energia comprada 1.118,999 MWh.

Cabe destacar que segundo o Banco de Informações de Geração (2020) da ANEEL, a UHE-Balbina (código UHE.PH.AM.000190-2.01), de propriedade da Amazonas Geração e Transmissão de Energia S.A., tem potência outorgada de 249.750 (kW) e energia assegurada de 132,30 (MW), tendo como destino final o Estado de São Paulo.

Atualmente, a energia de Balbina está sendo diretamente injetada no Sistema Interligado Nacional (SIN), portanto sendo contabilizada neste sistema. As Centrais Geradoras Hidrelétricas (CGH) e Pequenas Centrais Hidrelétricas (PCH) até 1 e 1 a $30 \mathrm{MW}$ de potência instalada, respectivamente, são isentas do pagamento de compensação financeira e cobrança pelo uso de recursos hídricos. A UHE-Balbina paga compensação 
financeira aos municípios de Presidente Figueiredo e de Urucará, por serem afetados pela barragem.

Deste modo, os repasses da compensação financeira pela utilização de recursos hídricos pagos pela UHE-Balbina iniciaram no ano de 1991, tendo como beneficiários o Estado do Amazonas e os municípios de Presidente Figueiredo e de São Sebastião do Uatumã, este último recebeu até o ano de 2001, quando o município de Urucará passou a ser beneficiário.

Neste ínterim, a CFURH da UHE-Balbina poderia ser uma das fontes do FERH, conforme previsão no artigo supracitado da PERH. Ressalta-se que estes dados só foram possíveis com as orientações repassadas por meio de e-SIC ANEEL $\mathrm{n}^{\text {o }}$ 48700004369201868, que disponibilizou o processo ANEEL no 48500.007053/2006-15, relacionados à CFURH da UHE-Balbina (Brasil, 2019). O presente demonstrativo financeiro, que contempla o período de janeiro de 1991 até dezembro de 2019, tem como referência o mês de competência de origem do pagamento, tomando-se como base o relatório emitido na data de crédito da Secretaria do Tesouro Nacional. 0 demonstrativo mostra que no período de 1991 a 2019 a UHE de Balbina gerou a título de compensação financeira ao Estado do Amazonas e aos municípios beneficiários o montante de $\mathrm{R} \$$ 83.512.819,56 desconsiderado os valores de outros beneficiários, como ANA, MDR, MME e FNDCT.

No período considerado, o Estado do Amazonas recebeu R\$39.739.486,34 e o município de Presidente Figueiredo o montante de R\$43.054.735,78, São Sebastião do Uatumã recebeu, entre 1991-2001, o valor de R\$37.942,96 e o município de Urucará recebeu, desde 2001 até o presente, exatos $\mathrm{R} \$ 680.654,48$.

Entre o ano 1991 até maio de 2018, o Estado do Amazonas e os Municípios de Presidente Figueiredo e de Urucará, juntos tiveram repasses de parcelas iguais, pois a Lei no 8.001/1990 (Brasil, 1990), e a Lei no 9.984/2000 (Brasil, 2000), estabeleceram o percentual de $45 \%$ para os estados e $45 \%$ para os municípios afetados pela barragem. Contudo, com a redação nova da Lei no 13.661/2018 (Brasil, 2018), os municípios passam a receber $65 \%$ (aumento de 20\%), e os estados passam a receber 25\% (redução de 20\%). Nesse novo cenário, a partir deste ano os recursos repassados ao Município de Presidente Figueiredo terão um aumento significativo e redução no repasse aos cofres do governo do Estado do Amazonas.

Os efeitos da nova lei podem ser observados a partir de 2018. Para exemplificar, os valores referentes ao ano de 2019, quando o Estado do Amazonas recebeu $\mathrm{R} \$ 1.280 .712,44$ e Presidente Figueiredo e Urucará, $\mathrm{R} \$ 3.329 .852,34$. Valor este que poderia ter impactos na Gestão de Recursos Hídricos, caso tivesse essa finalidade ao ser direcionado ao FERH. Esses valores são direcionados ao Caixa Único do Estado do Amazonas, que em teoria, segundo previsão da PERH, deveria ir para FERH, o que poderia dar mais operacionalidade para o financiamento das atividades e projetos PERH e fortalecimento dos componentes do SEGRH. Este fato só evidencia o não cumprimento da própria legislação estadual, que estabelece esta finalidade, situação esta similar às operações financeiras do Fundo Estadual de Meio Ambiente.

Nesse sentido, observa-se que na última década os valores anuais da compensação pagos ao Estado do Amazonas oscilaram entre mais de 1,6 a 2,4 milhões de reais, com máxima de mais de 2,8 milhões em 2013, portanto um valor considerável, que poderia mudar o cenário da Gestão de Recursos Hídricos no estado, quando bem administrado.

A Compensação Financeira pela Exploração de Recursos Minerais repassada ao Estado do Amazonas. 0 inciso III, do art. 34, da Lei no 3.167/2007, detalha como uma das receitas do FERH - a parte da compensação financeira que os Municípios e o Estado recebem com relação aos aproveitamentos de outros recursos minerais, para aplicação exclusiva em levantamentos, estudos e programas de interesse do gerenciamento de 
recursos hídricos subterrâneos. Nessa perspectiva, a Agência Nacional de Mineração (ANM) repassa mensalmente a Compensação Financeira pela Exploração de Recursos Minerais (CFEM) ao Estado do Amazonas e aos 22 municípios afetados pela extração de minerais, conforme dados de 2019 , sendo que do total, $15 \%$ vão para o estado e $60 \%$ aos municípios, atendendo ao que determina a Lei no 13.540/2017. Esses dados estão detalhados no Extra Sistema de Arrecadação da ANM, a partir de 2004.

Os dados de 2004 a 2019 mostram que o estado e municípios afetados receberam o montante de $\mathrm{R} \$ 93.976 .638,17$ de CFEM. 0 maior percentual desse repasse, que chega a ser mais de $80 \%$ - o equivalente a $\mathrm{R} \$ 77.229 .600,09$, referem-se principalmente pela extração de cassiterita, tantalita-columbita, granito, minério de nióbio e estanho, que ocorre no município de Presidente Figueiredo pela Mineração Taboca. Salienta-se que esta mineradora foi fundada em 1969 e atua principalmente na mineração e metalurgia de estanho e minerais industriais. No mercado mundial, atua principalmente com a extração do Estanho, possuindo mina própria, denominada Mina de Pitinga, possuindo longevidade estimada em 100 anos.

Conforme a ANM (2019), das 15 barragens localizadas no município de Presidente Figueiredo, que pertencem a empresa Mineração Taboca S.A., que atua com a exploração de Minério de Estanho Primário, oito estão inseridas na Política Nacional de Segurança de Barragens (PNSB), as demais não estão inseridas nessa política e uma delas apresenta dano potencial alto.

Neste cenário, considerando as condições apresentadas pelas barragens de Presidente Figueiredo, o Ministério Público Federal (MPF) em 2019, firmou acordo com a Mineradora Taboca S.A. com a finalidade de compensar danos ambientais causados pela extração de minério no município, que fica a $117 \mathrm{~km}$ de distância de Manaus. Com isso, a mineradora deve direcionar $\mathrm{R} \$ 7,9$ milhões em recursos para iniciativas em favor do meio ambiente.

A partir desse cenário da arrecadação de CFEM por parte do Amazonas e municípios afetados, em específico Presidente Figueiredo, que somados R \$ 93.976.638,17 em repasses de 2004 a 2019, e tendo como base legal o inciso III, art. 34, da Lei no 3.167/2007, que informa que parte da CFEM deve ir para o FERH. Percebe-se, que esses valores são repassados mensalmente ao Caixa Único do Estado, conforme dados do Portal da Transparência Fiscal da SEFAZ, contudo parte dessas receitas não são repassadas ao Fundo, conforme especifica a lei da Política Estadual de Recursos Hídricos, não existindo assim instrumentos capazes de verificar a aplicação dos recursos financeiros advindos desta Compensação.

Deste modo, o regimento interno do Fundo não estipula o percentual mensal de repasse de CFEM, conforme previsão da PERH. No entanto, uma portaria não tem a autonomia legal de capturar recursos do Caixa Único do Estado, isso só poderá ocorrer mediante promulgação de lei ou decreto. Sem essa explicitação legal do percentual, abre margem para que esse repasse não ocorra, fazendo com que esse recurso seja usado em outras áreas, diferentes daquelas previstas inicialmente. Isso envolve questões de dimensão política, pois envolve a atuação do secretário de Meio Ambiente junto à Câmara Legislativa ou Governo Estadual.

Os royalties do petróleo e do gás natural repassados ao Estado do Amazonas. Quanto às receitas do FERH previstas no art. 34, da Lei no 3.167/2007, fica evidente que parte da CFEM e da CFURH - incisos III e XI deverão ir para o Fundo, percentuais estes que devem ser regulamentados, mediante ato normativo. No entanto, outras compensações poderiam ser incorporadas nas receitas do FERH, entre elas, os royalties do petróleo e gás natural repassados ao Estado do Amazonas.

Como exemplo, cita-se o caso do Estado do Espírito Santo, que disponibiliza 0,5\% do produto da arrecadação proveniente da compensação financeira dos royalties do 
petróleo e do gás natural ao Fundo Estadual de Recursos Hídricos do Espírito Santo (FUNDÁGUA). Ressalta-se que o Espírito Santo é o segundo dos estados que mais arrecadam com esse tipo de royalties, ficando atrás somente do Rio de Janeiro, e, o Amazonas ficando em quarto. Somente de janeiro a outubro de 2019, últimos dados fornecidos pela ANP (2020), foram repassados aos cofres do Espírito Santo o montante de $\mathrm{R} \$$ 691.166.231,33, e, em 2018 chegou a R\$ 846.465.474,55. Tendo como referência 2018, $0,5 \%$ dos royalties de petróleo e gás repassados ao FUNDÁGUA, equivaleram-se a $\mathrm{R} \$ 4.232 .327,37$.

Nessa perspectiva, se o Amazonas adotasse essa metodologia de repasse de 0,5\% de royalties ao FERH, somente em 2018 seriam repassados $\mathrm{R} \$ 1.107 .424,78$, visto que neste ano o Estado recebeu $\mathrm{R} \$ 221.484 .956,83$. Sendo assim, essa seria uma nova possibilidade de receita para o Fundo, que precisa ser melhor debatida.

Detalhando melhor esses repasses, de janeiro a outubro de 2019, últimos dados divulgados pela ANP - conforme citado anteriormente, o Amazonas se beneficiou com $\mathrm{R}$ \$ 199.713.803,23 de royalties - sendo que, além da capital, outros 19 municípios também são beneficiados. A maior parcela destina-se ao município de Coari, onde está localizado o maior local de extração, que somente em outubro de 2019, recebeu o montante de $\mathrm{R} \$ 5.260 .664,61$. Na sequência, aparecem os Municípios de Codajás, de Anori, de Tefé, de Anamã e de Manaus, com os maiores repasses depois de Coari.

A partir dessas informações, entende-se, em consonância com Torronteguy (2009), que grande parte da arrecadação obtida com os royalties sobre a mineração e a extração de petróleo está vinculada a objetivos de ampliação e conservação do patrimônio ambiental e histórico e dos recursos hídricos. Essa vinculação é coerente com a ideia de que os royalties constituem venda de patrimônio público e que, portanto, as receitas auferidas devem ser aplicadas na ampliação e conservação de outras formas de patrimônio público.

Nesse cenário, cabe a vinculação de percentual de repasse financeiro dos royalties ao FERH/AM que o Estado do Amazonas recebe, de forma mensal ou anual, por meio de regulamentação, considerando que a vontade política incidirá sobre essa questão.

As multas aplicadas pelo Instituto de Proteção Ambiental do Amazonas com base na Política de Recursos Hídricos. 0 inciso X, do art. 34, da Política Estadual de Recursos Hídricos, estabelece que o produto da aplicação de multas cobradas dos infratores da legislação sobre recursos hídricos será uma das receitas previstas no FERH.

Nessa perspectiva, o Instituto de Proteção Ambiental do Amazonas (IPAAM) é o órgão responsável por aplicar essas multas, conforme prevê o inciso IV, do art. 57 da PERH. Para tanto, apesar da PERH ser promulgada em 2001, o IPAAM só disponibiliza em sua página institucional autos de infrações de 2016 a 2019.

Por meio do e-SIC IPAAM no 42/2019, informa-se que algumas multas que deveriam ser aplicadas pela Lei $n^{\circ}$ 3.167/2007 (Amazonas, 2007), que trata da PERH, regulamentado pelo Decreto $\mathrm{n}^{\mathrm{o}}$ 28.678/2009 (Amazonas, 2007), eram aplicadas diretamente pela Lei no 9.605/1998 (Brasil, 1998), que dispõe sobre as sanções penais e administrativas derivadas de condutas e atividades lesivas ao meio ambiente, regulamentada pelo Decreto no 6.514/2008 (Brasil, 2008). Consequentemente, pelo fato de muitas infrações relacionadas aos recursos hídricos serem aplicadas pela legislação federal, essas receitas eram direcionadas ao Fundo Estadual de Meio Ambiente (FEMA), deixando de ser repassadas ao Fundo Estadual de Recursos Hídricos (FERH) por falta de regulamentação.

O e-SIC IPAAM no 671/2019, traz informações complementares, onde são disponibilizados os autos de infração de 2016 a 2019. Neste cenário, é importante esclarecer que nos anos de 2016 e 2017 as multas aplicadas aos infratores de recursos hídricos tinham como base legal a Lei de Crimes Ambientais. Somente a partir de 2018 é 
que as multas começaram a ser aplicadas por meio da Lei no 3.167/2007 (Amazonas, 2007) e Decreto no 28.678/2009 (Amazonas, 2009).

No ano de 2018, aplicou-se R $\$ 150$ mil reais em multas cobradas aos infratores da legislação estadual de recursos hídricos, sendo que em 2019 aplicou-se R\$ 250 mil reais, totalizando $R \$ 400$ mil reais em multas pela PERH somente nesses dois últimos anos, que deveriam ser repassados ao FERH, conforme estabelece o inciso X, do art. 34, da Lei $\mathrm{n}^{\mathrm{o}}$ 3.167/2007 (Amazonas, 2007).

Cabe destacar que a maioria dessas multas foram oriundas de perfuração de poços por empresas privadas e condomínios de forma ilegal, localizados respectivamente em Manaus, Iranduba e Autazes, sem autorização do respectivo órgão competente, ou seja, o IPAAM.

Importante salientar que a maioria das infrações foram cometidas pela empresa responsável pelos serviços de abastecimento de água, coleta e tratamento de esgoto de Manaus, capital amazonense, onde somente em 2019 recebeu $\mathrm{R} \$ 150$ mil reais em multas por lançar efluentes de atividades doméstico/sanitário sem tratamento devido em curso de rios ou igarapés, infringindo condicionantes estabelecidas nas Licenças de Operação concedidas pelo IPAAM.

\section{Considerações finais}

Por meio deste estudo, buscou-se entender o funcionamento e gerenciamento do Fundo Estadual de Recursos Hídricos do Amazonas, instrumento econômico-financeiro da Política Estadual de Recursos Hídricos, instituído pela Lei no 2.712/2001 (Amazonas, 2001), cujo regimento interno, com os procedimentos de sua operacionalização, foi formalizado mediante a publicação da Portaria SEMA no 120/2019 (Amazonas, 2019). Neste cenário, a partir dos resultados encontrados, ponderaram-se as seguintes considerações:

- a instituição do regimento interno, no ano de 2019, traz procedimentos gerais necessários. No entanto, algumas questões deixaram de ser previstas, entre elas as receitas que irão constituir o FERH/AM, e quais os percentuais de repasse de cada uma delas. Outras questões, como pagamentos de despesas correntes da SEMA e IPAAM devem ser reavaliadas, considerando que as finalidades das despesas do Fundo não são estas;

- com relação às receitas e despesas que operacionalizam o FERH/AM, oriundas do Progestão - 1 Ciclo, considerando que este programa visa a aplicação financeira para ações de fortalecimento institucional e de gerenciamento de recursos hídricos. Importante destacar que este programa tem total alinhamento com os objetivos do Fundo, visto que estas receitas têm como finalidade atender as diretrizes da Política Estadual de Recursos Hídricos e os objetivos e metas do Plano Estadual de Recursos Hídricos;

- observou-se ainda que, dada a situação do quadro de pessoal reduzido do órgão executor (SEMA) e fiscalizador (IPAAM), faz-se necessário que a aplicação de parte dos recursos do Fundo seja direcionada para a contratação de recursos humanos que possam dar prosseguimento nas atividades administrativas e operacionais, sem o qual dificilmente haverá sustentabilidade na gestão de recursos hídricos do estado;

- quanto às modalidades de empréstimos previstos para o FERH-AM, especialmente o financiamento reembolsável, o que exige um agente financeiro (banco), percebeu-se que ainda está distante da realidade, necessitando de uma melhor regulamentação, assim como dos não reembolsáveis; 
- no que se refere à outras receitas que poderiam integrar as do FERH/AM e que deixam de fazer parte atualmente, percebeu-se que há previsão legal de repasses financeiros dos percentuais da CFEM, CFURH e multas aplicadas pela Política Estadual de Recursos Hídricos. No entanto, esses percentuais ainda não foram normatizados, por meio de resoluções ou outros instrumentos legais, regulamentando assim os incisos do art. 34, da Lei no 3.167/2007, o que acaba gerando a não obrigatoriedade do Estado em fazer esses repasses ao Fundo. Cabe salientar que as infrações com base nesta mesma lei, estão sendo repassados ao FEMA/AM, não ao FERH/AM, como previsto legalmente, no entanto, há previsão de repasse das multas oriundas das infrações para o ano de 2020; e

- tendo como referência outros FERHs, percebe-se que os mais bens implementados, utilizam percentual dos royalties do petróleo e do gás natural na constituição das receitas de seus Fundos, e apesar do Estado do Amazonas ser o quarto do Brasil no repasse de royalties, não prevê esse tipo de receita no FERH/AM, algo que poderia ser debatido no Conselho Estadual de Recursos Hídricos, visando sua regulamentação. Importante frisar que esse tipo de receita depende de regulamentação por lei, o que exige engajamento da assembleia legislativa estadual.

Consequentemente, estes obstáculos supramencionados resultaram na não operacionalização satisfatória do FERH/AM até os dias atuais, visto que para que haja um Fundo bem implementado, necessita-se de um Sistema Estadual de Gerenciamento de Recursos Hídricos bem fortalecido e consolidado, com Conselho Estadual de Recursos Hídricos atuante e Secretaria de Estado do Meio Ambiente propondo normatizações de suas operações financeiras, com base na Política Estadual de Recursos Hídricos.

Outro ponto refere-se a não complexidade da gestão hídrica no Estado do Amazonas, em comparativo com as grandes metrópoles, que possuem grandes problemas ambientais, entre eles, a mortandade de seus corpos hídricos, que influenciam inclusive no abastecimento público. Nestes cenários de poluição, os FERHs operam de forma satisfatória, por questões de saúde pública, sendo relevantes na recuperação de bacias hidrográficas. Contudo, não pode ser considerada como justificativa para que o FERH/AM não operacionalize de forma satisfatória, devendo o Poder Público priorizar essas ações em suas políticas públicas como forma de prevenção, não de correção de problemas ambientais.

Entende-se que, sem a questão política envolvida, especialmente quando se trata da regulamentação por lei ou decreto das receitas que os compõem, será difícil implementar o Fundo no contexto atual da gestão hídrica do estado.

Sendo assim, este estudo teve como finalidade criar subsídios para a tomada de decisões da Secretaria de Estado do Meio Ambiente, do Conselho Estadual de Recursos Hídricos e dos Comitês de Bacias Hidrográficas, quando se referir ao Fundo Estadual de Recursos Hídricos, além de contribuir com a comunidade acadêmica auxiliando novos pesquisadores a realizarem estudos acerca dessa temática, criando alternativas que auxiliem no desenvolvimento da gestão de recursos hídricos do Estado do Amazonas, fortalecendo assim o Sistema Estadual de Gerenciamento de Recursos Hídricos.

\section{Agradecimentos}

À Fundação de Amparo à Pesquisa do Estado do Amazonas (FAPEAM) pelo apoio financeiro concedido à realização dessa pesquisa, ao Mestrado Profissional em Rede Nacional em Gestão e Regulação de Recursos Hídricos (PROFÁGUA) e ao Projeto CAPES/ANA AUXPE no 2717/2015. 


\section{Conflito de interesses}

Os autores declaram não haver conflito de interesses.

\section{Referências}

ANA - Agência Nacional de Águas e Saneamento Básico. Conjuntura dos recursos hídricos no Brasil 2020: informe anual. Brasília: ANA, 2020.

ANA - Agência Nacional de Águas e Saneamento Básico. Contrato para participação do Amazonas no PROCOMITÊS entra em vigor. 2014. Disponível em: $<$ https://www.ana.gov.br/noticias/contrato-para-participacao-do-amazonas-noprocomites-entra-em-vigor>. Acesso em: 31 out. 2021.

ANA - Agência Nacional de Águas e Saneamento Básico. Conselho aprova Plano de Aplicação do Fundo Estadual de Recursos Hídricos. 2019. Disponível em: <https://www.ana.gov.br/noticias-antigas/conselho-aprova-plano-de-aplicaassapso-dofundo.2019-03-15.2733411940>. Acesso em: 31 jan. 2021.

ANA - Agência Nacional de Águas e Saneamento Básico. Direito de águas à luz da governança. Brasília: ANA, 2020. Disponível em: <https://www.gov.br/ana/pt$\mathrm{br} /$ assuntos/noticias-e-eventos/noticias/ana-lanca-livro-digital-direito-de-aguas-a-luzda-governanca-em-tres-idiomas/livro-direito-de-aguas-a-luz-da-governanca-pt.pdf> . Acesso em: 31 jan. 2021.

ANA - Agência Nacional de Águas e Saneamento Básico. Política Nacional de Recursos Hídricos. 2021. Disponível em: <https://www.ana.gov.br/gestao-da-agua/sistema-degerenciamento-de-recursos-hidricos>. Acesso em: 31 jan. 2021.

ANA - Agência Nacional de Águas e Saneamento Básico. O PROGESTÃo no Amazonas: síntese do primeiro ciclo do programa (2013-2017). Brasília: ANA, 2017. Disponível em: <https://progestao.ana.gov.br/portal/progestao/mapa/am/progestao_am_2015.pdf>.

Acesso em: 31 jan. 2021.

ANA - Agência Nacional de Águas e Saneamento Básico. Contrato no 115/ANA/2013PROGESTÃO. Brasília: ANA, 2013. Disponível em: <https://progestao.ana.gov.br/portal/ progestao/progestao-1/acompanhamento-programa/status-da-adesao/documentos-dasufs/contratos-progestao-1/contrato_progestao_115_2013_am_ver-1o-e-2o-aditivos.pdf>. Acesso em: 31 jan. 2021.

ANEEL - Agência Nacional de Energia Elétrica. SIGA - Sistema de Informações de Geração da ANEEL. Brasília: ANEEL, 2020. Disponível em: <https://app.powerbi.com/view?r=eyJrIjoiNjc40GYyYjQtYWM2ZC00YjllLWJIYmEtYzdkN TQ1MTc1NjM2IiwidCI6IjQwZDZmOWI4LWVjYTctNDZhMi05MmQ0LWVhNGU5YzAxNzBl MSIsImMiOjR9>. Acesso em: 31 jan. 2021.

ANM - Agência Nacional de Mineração. Arrecadação de CFEM. 2019. Disponível em: <https://sistemas.anm.gov.br/arrecadacao/extra/relatorios/arrecadacao_cfem.aspx>. Acesso em: 31 jan. 2021.

ANP - Agência Nacional do Petróleo, Gás Natural e Biocombustíveis. Royalties. 2020. Disponível em: <http://www.anp.gov.br/royalties-e-outras-participacoes/royalties>. Acesso em: 31 jan. 2021.

Amazonas. Decreto no 28.678, de 16 de junho de 2009. Regulamenta a Lei no 3.167 , de 28 de agosto de 2007, que reformula as normas disciplinadoras da Política Estadual de Recursos Hídricos e do Sistema Estadual de Gerenciamento de Recursos Hídricos, e dá 
outras providências. Disponível em: <http://www.meioambiente.am.gov.br/wpcontent/uploads/2016/08/Decreto-28.678-16-de-junho-de-2009.pdf>. Acesso em: 31 jan. 2021.

Amazonas. Decreto no 34.059, de 9 de outubro de 2013. Dispõe sobre a adesão do Estado do Amazonas ao Pacto Nacional pela Gestão das Águas, e dá outras providências. Disponível em: <https://progestao.ana.gov.br/progestao-1/acompanhamentoprograma/status-da-adesao/documentos-das-ufs/decretos-de-adesao/decreto-34059_09_10_2013_amazonas.pdf>. Acesso em: 31 jan. 2021.

Amazonas. Decreto no 36.819, de 31 de março de 2016. Regulamenta o acesso à informação no âmbito do Poder Executivo Estadual. Disponível em: <http://www.transparencia.am.gov.br/wp-content/uploads/2016/04/DIARIO_OFICIAL_ _33253.pdf>. Acesso em: 31 jan. 2021.

Amazonas. Instituto de Proteção Ambiental do Amazonas. Transparência - Técnica. 2020. Disponível em: <http://www.ipaam.am.gov.br/transparencia-2019/>. Acesso em: 31 jan. 2021.

Amazonas. Lei no 2.712, de 28 de dezembro de 2001. Disciplina a Política Estadual de Recursos Hídricos, estabelece o Sistema Estadual de Gerenciamento de Recursos Hídricos e dá outras providências. Disponível em: <http://meioambiente.am.gov.br/wpcontent/uploads/2016/08/1-Lei-N\%C2\%BA-2.712-de-2001.pdf>. Acesso em: 31 jan. 2021.

Amazonas. Lei no 3.167, de 28 de agosto de 2007. Reformula as normas disciplinadoras da Política Estadual de Recursos Hídricos e do Sistema Estadual de Gerenciamento de Recursos Hídricos, e estabelece outras providências. Disponível em: <https://progestao.ana.gov.br/panorama-dos-estados/am/lei-no-3167-07_am.pdf>. Acesso em: 31 jan. 2021.

Amazonas. Portaria SEMA no 120, de 13 de novembro de 2019. Regimento interno do Fundo Estadual de Recursos Hídricos. Disponível em: <http://meioambiente.am.gov.br/wp-content/uploads/2016/03/6-PORTARIAN\%C2\%BA120-Regimento-do-FERH.pdf>. Acesso em: 31 jan. 2021.

Amazonas. Acesso à Informação (e-SIC). 2021. Disponível em: <https://acessoainformacao.am.gov.br/index/>. Acesso em: 31 jan. 2021.

Brasil. Instrumentos de gestão das águas. Brasília: Edições Câmara, 2015.

Brasil. Constituição da República Federativa do Brasil de 1988. Disponível em: $<$ http://www.planalto.gov.br/ccivil_03/constituicao/constituicao.htm>. Acesso em: 31 jan. 2021.

Brasil. Lei no 9.433, de 8 de janeiro de 1997. Institui a Política Nacional de Recursos Hídricos e cria o Sistema Nacional de Gerenciamento de Recursos Hídricos. Disponível em: <http://www.planalto.gov.br/ccivil_03/leis/L9433.htm>. Acesso em: 28 fev. 2021.

Brasil. Lei no 9.605, de 12 de fevereiro de 1998. Dispõe sobre as sanções penais e administrativas derivadas de condutas e atividades lesivas ao meio ambiente, e dá outras providências. Disponível em: <http://www.planalto.gov.br/ccivil_03/leis/l9605.htm>. Acesso em: 28 fev. 2021.

Brasil. Decreto no 6.514, de 22 de julho de 2008. Dispõe sobre as infrações e sanções administrativas ao meio ambiente, estabelece o processo administrativo federal para apuração destas infrações, e dá outras providências. Disponível em: 
<http://www.planalto.gov.br/ccivil_03/_ato2007-2010/2008/decreto/d6514.htm>. Acesso em: 28 fev. 2021.

Brasil. Lei no 12.527, de 18 de novembro de 2011. Regula o acesso a informações previsto no inciso XXXIII do art. 5ำ, no inciso II do $\S 3^{\circ}$ do art. 37 e no $\S 2^{\circ}$ do art. 216 da Constituição Federal; altera a Lei no 8.112, de 11 de dezembro de 1990; revoga a Lei no 11.111, de 5 de maio de 2005, e dispositivos da Lei no 8.159, de 8 de janeiro de 1991; e dá outras providências. Disponível em: <http://www.planalto.gov.br/ccivil_03/_ato20112014/2011/lei/l12527.htm>. Acesso em: 31 jan. 2021.

Brasil. Fundos ambientais estaduais com potencial de apoio ao desenvolvimento florestal. Brasília: MMA/FDF, 2016.

Brasil. Plataforma Integrada de Ouvidoria e Acesso à Informação. Sistema Eletrônico do Serviço de Informação (e-SIC). Acesso à Informação. 2019. Disponível em: <https://falabr.cgu.gov.br/publico/Manifestacao/SelecionarTipoManifestacao.aspx?Retur nUrl=/> . Acesso em: 31 jan. 2021.

Dias, F. O. O Fundo Estadual de Recursos Hídricos do Amazonas: panorama do seu funcionamento e desafios para a gestão. Manaus: Universidade do Estado do Amazonas, Escola Normal Superior, 2020. (Dissertação de mestrado).

Eletrobras Distribuição Amazonas. Demonstrações financeiras e relatório da administração da Eletrobras Distribuição Amazonas. 2017. Disponível em: $<$ https://eletrobras.com/pt/ri/Paginas/Demonstracoes-das-Empresas-de-Transmissao-eGeracao.aspx>. Acesso em: 31 jan. 2021.

MPF - Ministério Público Federal. MPF firma acordo com mineradora para apoio financeiro a projetos ambientais no AM. 2019. Disponível em: <http://www.mpf.mp.br/am/sala-deimprensa/noticias-am/mpf-firma-acordo-com-mineradora-para-apoio-financeiro-aprojetos-ambientais-no-am>. Acesso em: 31 jan. 2021.

Rodrigues, R. G. Fundo Estadual de Recursos Hídricos do Rio de Janeiro: diagnóstico do seu funcionamento e desafios. Rio de Janeiro: Universidade Federal do Rio de Janeiro, Instituto Alberto Luiz Coimbra de Pós-Graduação e Pesquisa de Engenharia, 2007. (Dissertação de mestrado).

Silva, A. H.; Fossá, M. I. T. Análise de conteúdo: exemplo de aplicação da técnica para análise de dados qualitativos. Qualit@s Revista Eletrônica, v. 17, n. 1, p. 1-14, 2015. https://doi.org/10.18391/qualitas.v16i1.2113

Torronteguy, A. F. A aplicação dos royalties do petróleo e a efetividade dos direitos fundamentais sociais. Vitória: Faculdade de Direito de Vitória, 2009. (Dissertação de mestrado).

TCE-AM - Tribunal de Contas do Estado do Amazonas. Busca simplificada. 2020. Disponível em: <https://servicos.tce.am.gov.br/servicos/pages/processo/consulta _simples.jsf>. Acesso em: 31 jan. 2021.

Informação da Licença: Este é um artigo Open Access distribuído sob os termos da Licença Creative Commons Attribution, que permite uso irrestrito, distribuição e reprodução em qualquer meio, desde que a obra original seja devidamente citada. 